\title{
Bothrops pirajai snake venom L-amino acid oxidase: in vitro effects on infection of Toxoplasma gondii in human foreskin fibroblasts
}

\author{
Luiz F. M. Izidoro, ${ }^{1,2}$ Lívia M. Alves, ${ }^{1}$ Veridiana M. Rodrigues, ${ }^{2}$ \\ Deise A. O. Silva, ${ }^{3}$ José R. Mineo ${ }^{3, *}$
}

${ }^{1}$ Faculdade de Ciências Integradas do Pontal, Universidade Federal de Uberlândia, Brazil,

${ }^{2}$ Laboratório de Química de Proteinas e Produtos Naturais, Instituto de Genética e Bioquímica, Universidade Federal de Uberlândia, Brazil,

${ }^{3}$ Laboratório de Imunoparasitologia, Instituto de Ciências Biomédicas, Universidade Federal de Uberlândia, Brazil.
Revista Brasileira de Farmacognosia Brazilian Journal of Pharmacognosy 21(3): 477-485, May./Jun. 2011

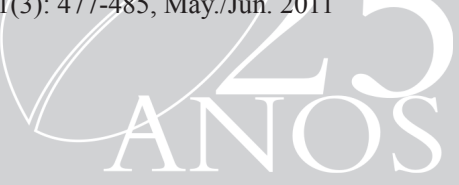

\section{Article}

Received 16 Jul 2010

Accepted 17 Jan 2011

Available online 17 Jun 2011

Keywords:

L-amino acid oxidase

Bothrops pirajai

human fibroblasts

snake venom

Toxoplasma gondii

ISSN 0102-695X doi: $10.1590 /$ S0102-695X2011005000108

\section{Introduction}

Bothrops pirajai snake is an endemic species from the South region of Bahia state, Brazil, and it belongs nowadays to a national list of Brazilian fauna species threatened of extinction (Martins \& Molina, 2008). Its venom is rich in proteins such as phospholipases $\mathrm{A}_{2}$, desintegrins, metalloproteases, serinoproteases, L-amino acid oxidases and others (Rodrigues et al., 2009). L-amino acid oxidases (LAAO, EC 1.4.3.2) are enantioselective flavoenzymes catalyzing the oxidative deamination of a wide range of L-amino acids (Stábeli et al., 2007). During the reductive half-reaction, the amino acid substrate is oxidized to the imino acid with concomitant reduction of the flavin adenine dinucleotide (FAD) cofactor. The imino acid product of oxidation undergoes a non- enzymatic hydrolysis to give the respective $\alpha$-keto acid and ammonia. An oxidative half-reaction completes the catalytic cycle re-oxidizing the FAD with molecular oxygen and producing hydrogen peroxide (Moustafa et al., 2006).

BpirLAAO-I is an L-amino acid oxidase isolated from Bothrops pirajai snake venom by molecular exclusion, affinity and hydrophobic chromatography (Izidoro et al., 2006). It is a homodimeric acid glycoprotein with molecular mass of $130 \mathrm{kDa}$ and isoelectric point (pl) 4.9. Also, it was shown that BpirLAAO-I demonstrates bactericidal activity against Escherichia coli and Pseudomonas aeruginosa, in addition to cytotoxic activity against tumor cells, mouse paw edema, and typical fago (M13mp18) DNA fragmentation (Izidoro et al., 2006).

$$
\text { Anti-protozoan activities have been }
$$


investigated in many snake venom components. For example, L-amino acid oxidases from Bothrops spp were responsible for in vitro killing of Plasmodium falciparum (Zieler et al., 2001), Leishmania spp (Izidoro et al, 2006), and Trypanosoma cruzi (França et al., 2007). Neuwiedase, a metalloproteinase from Bothrops neuwiedi, showed a considerable effect against Toxoplasma gondii infection in vitro (Bastos et al., 2008).

T. gondii is a ubiquitous obligate intracellular parasite of the Phylum Apicomplexa and it is unusual within this group due to its capacity to infect a diverse array of cell types and virtually any warm-blooded animal. It is also remarkable the diversity of strategies that the parasite achieves for its essential intracellular survival (Miller et al., 2009). There are three infectious stages in the life cycle of $T$. gondii i.e. tachyzoites, bradyzoites contained in tissue cysts, and sporozoites contained in sporulated oocysts (Tenter et al., 2000). Tachyzoites actively and rapidly enter cells, and colonize within a highly modified parasitophorous vacuole that resists endosomal acidification. After six to eight parasite divisions the host cell lyses, and released tachyzoites infect surrounding cells and tissues, characterizing the acute phase of infection. Chronic infection is associated with differentiation into bradyzoites that form quiescent cysts within tissues of the central nervous system and skeletal muscle (Denkers, 2003).

T. gondii has both asexual and sexual phases in its life cycle, but the sexual stages of the parasite only occur in the intestine of felids, mainly the cat, as its definitive host, resulting in the excretion of oocysts in the feces. Thus, one way that humans and other warm-blooded animals can be infected is by swallowing oocysts that contaminate food, water or the environment. A second way of transmission of $T$. gondii to humans is by the consumption of undercooked meat containing tissue cysts from a variety of animals that are susceptible to infection, including sheep, pigs, and poultry. Finally, T. gondii tachyzoites can also be transmitted from mother to developing fetus, leading to congenital disease (Black \& Boothroyd, 2000). Toxoplasmosis in humans is commonly asymptomatic, but the symptoms can vary depending on the immune status of the patient and the clinical setting, that is, ocular or congenital toxoplasmosis (Montoya \& Liesenfeld, 2004; Sharif et al., 2007).

Current therapies for toxoplasmosis have been limited due to host toxicity and side effects, particularly for sulfa drugs (Kim et al., 2007). Considering that the treatment shows limited efficacy due to their substantial side effects, particularly in immunocompromised individuals and pregnant women, alternative therapies have been investigated by using chemical substances derived from plants, animals and microorganisms, as well as natural toxins and their derivatives (Tempone et al., 2007; Bastos et al., 2008). The aim of this study was to evaluate the effects of BpirLAAO-I on infection of Toxoplasma gondii in human foreskin fibroblasts in vitro.

\section{Materials and Methods}

Bothrops pirajai snake venon and BpirLAAO-I toxin

Crude Bothrops pirajai snake venom was obtained from Serpentário Proteínas Bioativas Ltda., Batatais, Brazil. BpirLAAO-I toxin was isolated and purified using a combination of molecular exclusion, affinity, and hydrophobic chromatography steps, as previously described (Izidoro et al., 2006). BpirLAAO-I is a homodimeric acid glycoprotein with approximate molecular weight of $130 \mathrm{kDa}$ and $\mathrm{pI}$ of 4.9 , displays high specificity toward hydrophobic/aromatic amino acids, and deglycosylation does not alter its enzymatic activity (Izidoro et al., 2006). In the present study, the protein concentration of the purified enzyme was determined by Bradford (1976).

\section{Toxoplasma gondii tachyzoites}

Tachyzoites of the virulent $\mathrm{RH}$ strain of T. gondii were maintained by intraperitoneal serial passages in Swiss mice at regular $48 \mathrm{~h}$ intervals (Mineo et al., 1980). Peritoneal exudates were harvested and washed twice $\left(720 \times \mathrm{g}, 10 \mathrm{~min}, 4{ }^{\circ} \mathrm{C}\right)$ in RPMI 1640 medium (Gibco, Paisley, UK). The pellet was suspended in $5 \mathrm{~mL}$ of medium and viable parasites were counted in hemocytometric chamber by Trypan blue dye exclusion.

\section{Human foreskin fibroblast culture}

Human foreskin fibroblasts (HFF) were obtained from American Type Culture Collection (ATCC, Manassas, USA) and cultured in $25 \mathrm{~cm}^{2}$ flasks until confluence in RPMI medium supplemented with 25 $\mathrm{mM}$ HEPES, $2 \mathrm{mM}$ L-glutamine, $100 \mathrm{U} / \mathrm{mL}$ penicillin, $100 \mu \mathrm{g} / \mathrm{mL}$ streptomycin (Sigma Chemical Co., St. Louis, USA) and 10\% heat-inactivated fetal calf serum (Cultilab, Campinas, Brazil) (complete RPMI) in a humidified incubator at $37^{\circ} \mathrm{C}$ and $5 \% \mathrm{CO}_{2}$.

\section{Cytotoxicity assay}

Cytotoxicity of BpirLAAO-I was assessed by determining HFF cell viability using MTT assays (Mosmann, 1983). HFF cells were cultured in 96-well plates $\left(1 \times 10^{5}\right.$ cells/well $)$ in triplicate in complete RPMI 
medium in the presence of double serial dilutions of BpirLAAO-I (from 20 to $0.3 \mu \mathrm{g} / \mathrm{mL}$ ) in complete medium, for $24 \mathrm{~h}$ at $37{ }^{\circ} \mathrm{C}$ and $5 \% \mathrm{CO}_{2}$. As controls, cells were incubated with complete medium alone. Cells were washed and pulsed with $10 \mu \mathrm{L}$ of thiazolyl blue (MTT, Sigma Chemical Co.) at $5 \mathrm{mg} / \mathrm{mL}$ in 90 $\mu \mathrm{L}$ of complete RPMI medium $4 \mathrm{~h}$ prior to the end of the culture. Formazan particles were solubilized in $10 \%$ sodium dodecyl sulfate and $50 \%$ N,N-dimethyl formamide. The optical density was determined after $30 \mathrm{~min}$ at $570 \mathrm{~nm}$ in a plate reader (Titertek Multiskan Plus, Flow Laboratories, McLean, USA). Results were expressed as percentage of cell viability in relation to controls. The median cytotoxic dose of BpirLAAO-I for HFF cells ( $50 \%$ cytotoxic dose - TD50) was calculated by extrapolation of a sigmoidal dose-response curve on a nonlinear regression plot with $95 \%$ confidence intervals (CI), corresponding to the cell viability $50 \%$ point, by using the GraphPad Prism software (GraphPad Software Inc., San Diego, USA) as previously described (Jones-Brando et al., 2006).

BpirLAAO-I treatment of $\mathrm{T}$. gondii tachyzoites before infection of HFF cells

HFF cells were cultured on 13-mm round glass coverslips into $24-w e l l$ plates $\left(1 \times 10^{5}\right.$ cells/well/200 $\left.\mu \mathrm{L}\right)$ for $24 \mathrm{~h}$ at $37{ }^{\circ} \mathrm{C}$ and $5 \% \mathrm{CO}_{2} . T$. gondii tachyzoites were pretreated for $1 \mathrm{~h}$ at $37{ }^{\circ} \mathrm{C}$ and $5 \% \mathrm{CO} 2$ with double serial dilutions of BpirLAAO-I (from 5 to $0.3 \mu \mathrm{g} / \mathrm{mL}$ ) or with medium alone. Next, parasites were centrifuged (720 x $g, 10 \mathrm{~min}$ ), washed once with medium, and then incubated with HFF cell monolayers on glass coverslips at a 5:1 (parasite:host-cell) ratio of infection. After $24 \mathrm{~h}$ of incubation at $37{ }^{\circ} \mathrm{C}$ and $5 \% \mathrm{CO}_{2}$, cells were washed with phosphate-buffered saline (PBS, $\mathrm{pH}$ 7.2), fixed in $10 \%$ buffered formalin for $2 \mathrm{~h}$ and stained with $1 \%$ toluidine blue. Coverslips were mounted on glass slides and cells were examined under light microscope with regards to the infection index (percentage of infected cells per 100 examined cells) and parasite intracellular replication (mean number of parasites per cell in 100 infected cells) (Bastos et al., 2008). Results were also expressed as percentages of inhibition of infection or inhibition of intracellular replication of each treatment in relation to controls (100\% of infection). Three slides of each treatment condition were assessed by two independent observers. The median inhibitory dose (50\% inhibitory dose - ID50) was calculated as described for TD50. For each treatment, a selectivity index (SI) was also calculated as described elsewhere (Nan et al., 2004), representing the ratio of the median cytotoxic dose (TD50) by the median inhibitory dose (ID50) for in vitro experiments.
BpirLAAO-I treatment of HFF cells after infection with T. gondii tachyzoites

HFF cell monolayers were washed with RPMI medium and infected with $T$. gondii RH strain tachyzoites at a 5:1 (parasite:host-cell) ratio of infection. After $3 \mathrm{~h}$ of incubation, cells were again washed to remove nonadherent parasites and then treated in triplicate with double serial dilutions of BpirLAAO-I (from 5 to $0.3 \mu \mathrm{g} / \mathrm{mL}$ ). As controls, infected cells were incubated with medium alone. After $24 \mathrm{~h}$ of incubation at $37^{\circ} \mathrm{C}$ and $5 \%$ of $\mathrm{CO}_{2}$, cells were examined and results were expressed as described above. Three slides of each treatment condition were assessed by two independent observers.

\section{Statistical analysis}

Statistical analysis and graphs were performed using the GraphPad Prism software version 4.0 (GraphPad Software Inc.). Comparison between groups was done using ANOVA and Bonferroni's multiple comparison test. Statistical significance was established when $p<0.05$.

\section{Results}

Cytotoxic activity was determined by screening different concentrations $(0.3-20 \mu \mathrm{g} / \mathrm{mL})$ of BpirLAAO-I on HFF cells (Figure 1). The dosing interval $(0.3$ to $5 \mu \mathrm{g} / \mathrm{mL})$ of BpirLAAO-I resulted in cell viability above $80 \%$, which was adopted as criteria for further experiments. The TD50 of BpirLAAO-I was established in $11.8 \mu \mathrm{g} / \mathrm{mL}$ (Figure 1; Table 1).

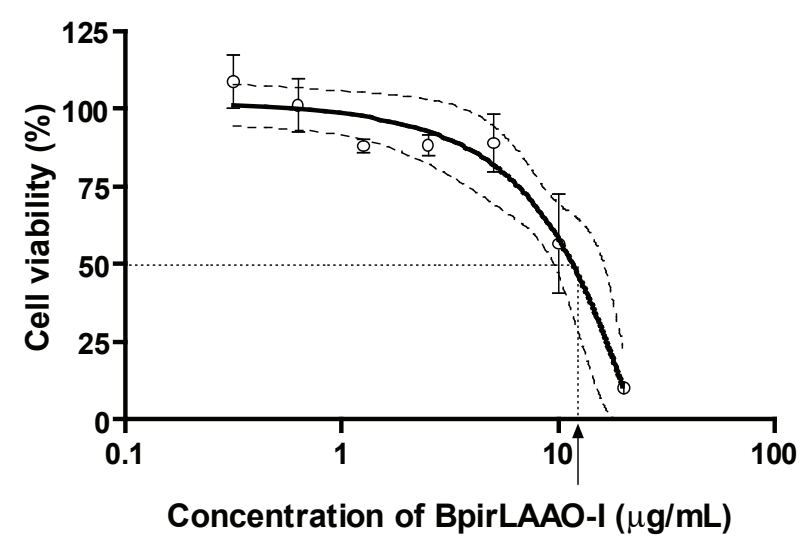

Figure 1. In vitro cytotoxic activity of BpirLAAO-I determined by MTT assays. Human fibroblasts were cultivated in the absence or presence of different concentrations (20 to $0.3 \mu \mathrm{g} / \mathrm{mL}$ ) of BpirLAAO-I for $24 \mathrm{~h}$. Results are expressed as mean and standard deviations of percentages of viable cells in relation to the controls and are plotted in a nonlinear regression sigmoidal dose-response curve with 95\% confidence intervals. Dotted lines show BpirLAAO-I concentration that corresponds to $50 \%$ of cell viability and 
Table 1. In vitro inhibition of Toxoplasma gondii infection in human fibroblasts under different treatment conditions with BpirLAAO-I isolated from Bothrops pirajai venom snake.

\begin{tabular}{lccccc}
\hline \multirow{2}{*}{ Treatment } & $\mathrm{TD}_{50}{ }^{\mathrm{c}}$ & \multicolumn{2}{c}{$\mathrm{ID}_{50}{ }^{\mathrm{d}}(\mu \mathrm{g} / \mathrm{mL})$} & \multicolumn{2}{c}{$\mathrm{SI}^{\mathrm{e}}$} \\
\cline { 2 - 6 } & $(\mu \mathrm{g} / \mathrm{mL})$ & Infection & Replication & Infection & Replication \\
\hline Before infection $^{\mathrm{a}}$ & 11.80 & 1.83 & 3.14 & 6.45 & 3.76 \\
After infection $^{\mathrm{b}}$ & 11.80 & 1.20 & $\mathrm{ND}^{\mathrm{f}}$ & 9.83 & $\mathrm{ND}^{\mathrm{f}}$ \\
\hline
\end{tabular}

${ }^{a}$ Treatment of $T$. gondii RH strain tachyzoites with different concentrations of BpirLAAO-I (serial double dilutions from 5 to $0.3 \mu \mathrm{g} / \mathrm{mL}$ ) before infection of human fibroblasts; ' Treatment of human fibroblasts with different concentrations of BpirLAAO-I (serial double dilutions from 5 to $0.3 \mu \mathrm{g} / \mathrm{mL}$ ) after infection with $T$. gondii tachyzoites; 'TD50: Toxic dose of $50 \%$ in human fibroblasts; dD50: Inhibitory dose of $50 \%$ in relation to the parameters of infection and parasite intracellular replication; ${ }^{\mathrm{e} S I}$ : Selectivity index $=$ TD50/ID50; ${ }^{\mathrm{f}}$ Not determined as no $50 \%$ inhibition was obtained.

the arrow indicates the median cytotoxic dose.

The treatment of $T$. gondii tachyzoites with different BpirLAAO-I concentrations before infection of host cells showed a dose-dependent decrease in the infection index (Figure 2A). A significant effect of BpirLAAO-I was observed for concentrations from 1.25 to $5 \mu \mathrm{g} / \mathrm{mL}$ in relation to untreated controls (Figure 2A). A similar profile with significant dose-dependent decrease in the infection index, starting from 1.25 to 5 $\mu \mathrm{g} / \mathrm{mL}$ of BpirLAAO-I was found for treatment of host cells after parasite infection (Figure 2C).

The mean number of intracellular parasites in host cells infected with tachyzoites previously treated with different concentrations of BpirLAAO-I decreased when enzyme concentrations increased, although significant differences were found only at $5 \mu \mathrm{g} / \mathrm{mL}$ of enzyme as compared to untreated controls (Figure 2B). In contrast, when $T$. gondii-infected HFF cells were treated with BpirLAAO-I, no enzyme concentration was effective in reducing the mean number of intracellular parasites as compared to untreated controls (Figure 2D). As illustrated in Figure 3, the amount of parasites within the parasitophorous vacuole decreased when parasites were treated before infection (Figure 3A), as compared to untreated infected cells (Figure 3B). Also, the treatment with the enzyme did not alter the host cell
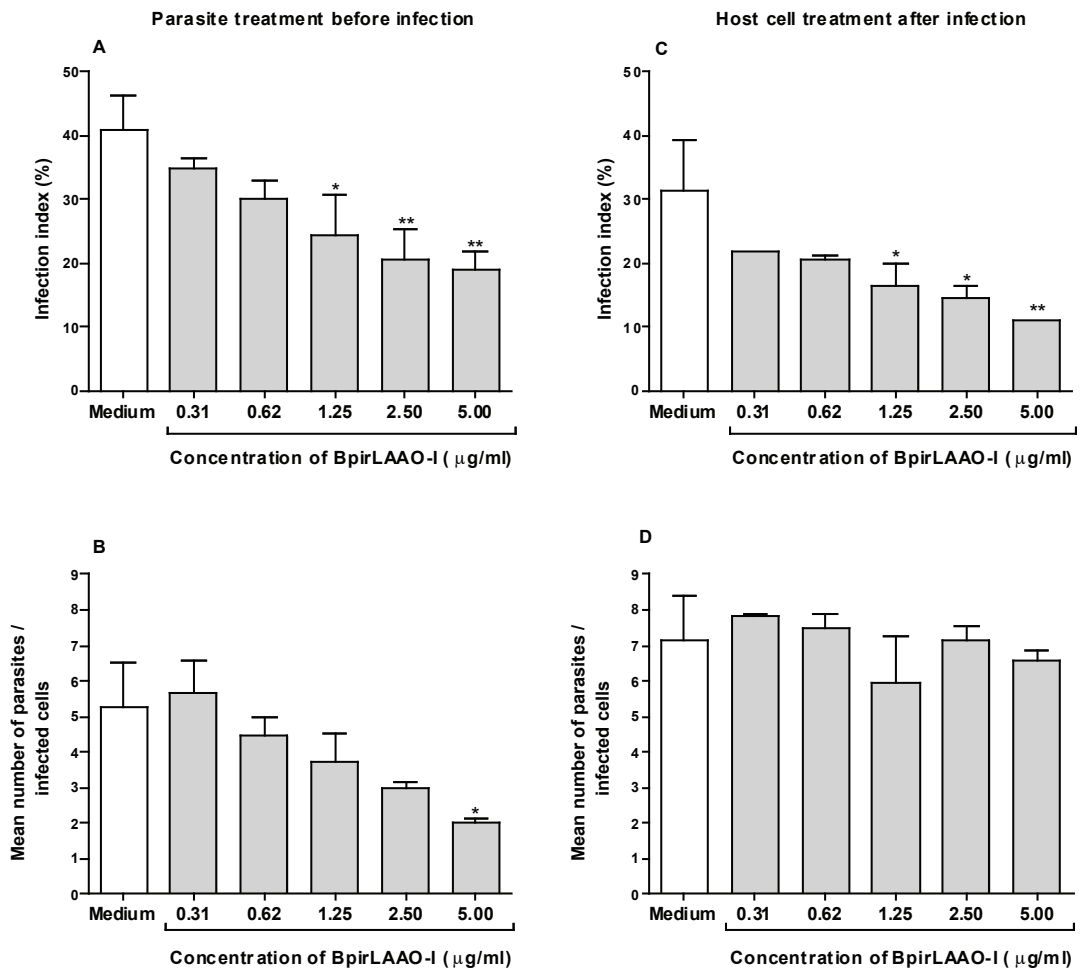

Figure 2. In vitro effects of BpirLAAO-I treatment on $T$. gondii infection and intracellular replication. The index of infection (percentage of infected cells in 100 examined cells) and the parasite replication (mean number of parasites per 100 infected cells) on human fibroblasts were evaluated under two different experimental conditions. (A, B) BpirLAAO-I treatment of $T$. gondii tachyzoites before infection of fibroblasts. (C, D) BpirLAAO-I treatment of fibroblasts after T. gondii infection. Bars represent mean and standard deviation of three analyses for each condition. Statistically significant differences in relation to medium $(* p<0.05 ; * * p<0.01)$. 

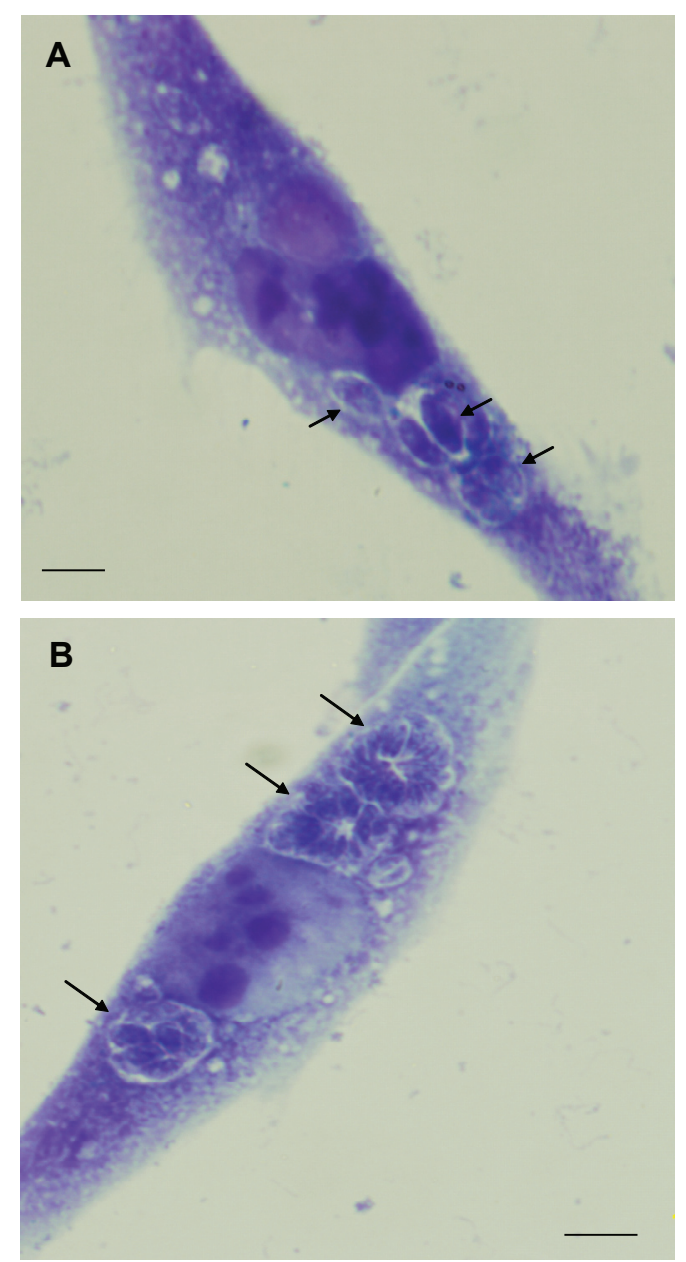

Figure 3. Photomicrographs of human fibroblasts infected with T. gondii tachyzoites previously treated with BpirLAAO-I at 5 $\mu \mathrm{g} / \mathrm{mL}$ (A) and untreated infected cells (B) after $24 \mathrm{~h}$ of infection. The presence of parasitophorous vacuoles (arrows) inside a single host cell was observed in both conditions. Note the considerable decrease in the number of parasites within the parasitophorous vacuoles after BpirLAAO-I treatment (A) compared to multiple generations of tachyzoites inside the parasitophorous vacuoles in untreated cells (B). Bar scale: $10 \mu \mathrm{m}$.

morphology or its replication.

The curves of inhibition of $T$. gondii infection on HFF cells when parasites were pretreated with different concentrations of BpirLAAO-I (Figure 4A) or when previously infected cells were treated with BpirLAAO-I (Figure 4C) showed a dose-dependent inhibition in relation to untreated controls. The ID50 of BpirLAAO-I was calculated and established in 1.83 $\mu \mathrm{g} / \mathrm{mL}$ for treatment before infection and $1.20 \mu \mathrm{g} / \mathrm{mL}$ for treatment after infection (Table 1).

Concerning the inhibition of parasite intracellular replication, the treatment of $T$. gondii tachyzoites before infection of host cells with BpirLAAO-I showed a curve of dose-dependent inhibition in relation to untreated controls, with ID50 of enzyme determined at $3.14 \mu \mathrm{g} / \mathrm{mL}$ (Figure 4B; Table 1). In contrast, the treatment of $T$. gondii-infected cells with the tested concentrations of BpirLAAO-I showed no inhibition of intracellular parasite replication in relation to untreated controls, and the ID50 could not be determined (Figure 4D; Table 1).

The selectivity indexes (SI) calculated for the infection index and intracellular replication were 6.45 and 3.76, respectively, for the BpirLAAO-I treatment of parasites before infection. In contrast, a higher SI (9.83) was obtained for the infection index when BpirLAAO-I treatment was performed after infection, whereas SI could not be calculated for the parasite intracellular replication, since no $50 \%$ inhibition was obtained (Table 1).

\section{Discussion}

Snake venoms belong to the most concentrated secretory fluids of vertebrates, consisting mainly of proteins and peptides generally termed toxins. These are primarily responsible for well-known biological effects and employed in several diagnostic and therapeutic approaches (Oliveira et al., 2009; Costa et al., 2009). The toxicity of the snake venom has been attributed to a class of toxins, the L-amino acid oxidases (svLAAO), although the precise mechanism of action of these enzymes and their role in snake toxicity are not well understood. Previous studies have reported that svLAAO may be related to defense mechanisms against natural agents, as parasites and bacteria (Iijima et al., 2003; Nuutinen \& Timonen, 2008; Kitani et al., 2008).

The anti-parasite effect of snake venoms can be also attributed to LAAO as previously described in the killing of Leishmania spp. (Tempone et al., 2001; Izidoro et al., 2006), Plasmodium falciparum (Zieler et al., 2001), and Trypanosoma cruzi (França et al., 2007). In the present study, we demonstrated for the first time the in vitro effects of a svLAAO isolated from Bothrops pirajai (BpirLAAO-I) on infection of $T$. gondii in human fibroblasts. Initially, we evaluated the cytotoxic activity of BpirLAAO-I on host cells, showing a dose-dependent cytotoxicity with TD50 established at $11.8 \mu \mathrm{g} / \mathrm{mL}$. The probable mechanisms of cytotoxicity induced by LAAO involve necrosis, apoptosis, or depletion of essential amino acids in the culture medium by enzymatic oxidation (Butzke et al., 2005). The process of necrosis could be related to the direct action of hydrogen peroxide on the cell plasma membrane, since the mechanism of apoptosis in the development of morphological and biochemical changes leads to cell death (Ande et al., 2006). Therefore, most of the biological effects of LAAO may be due to the secondary effect of hydrogen peroxide generated 

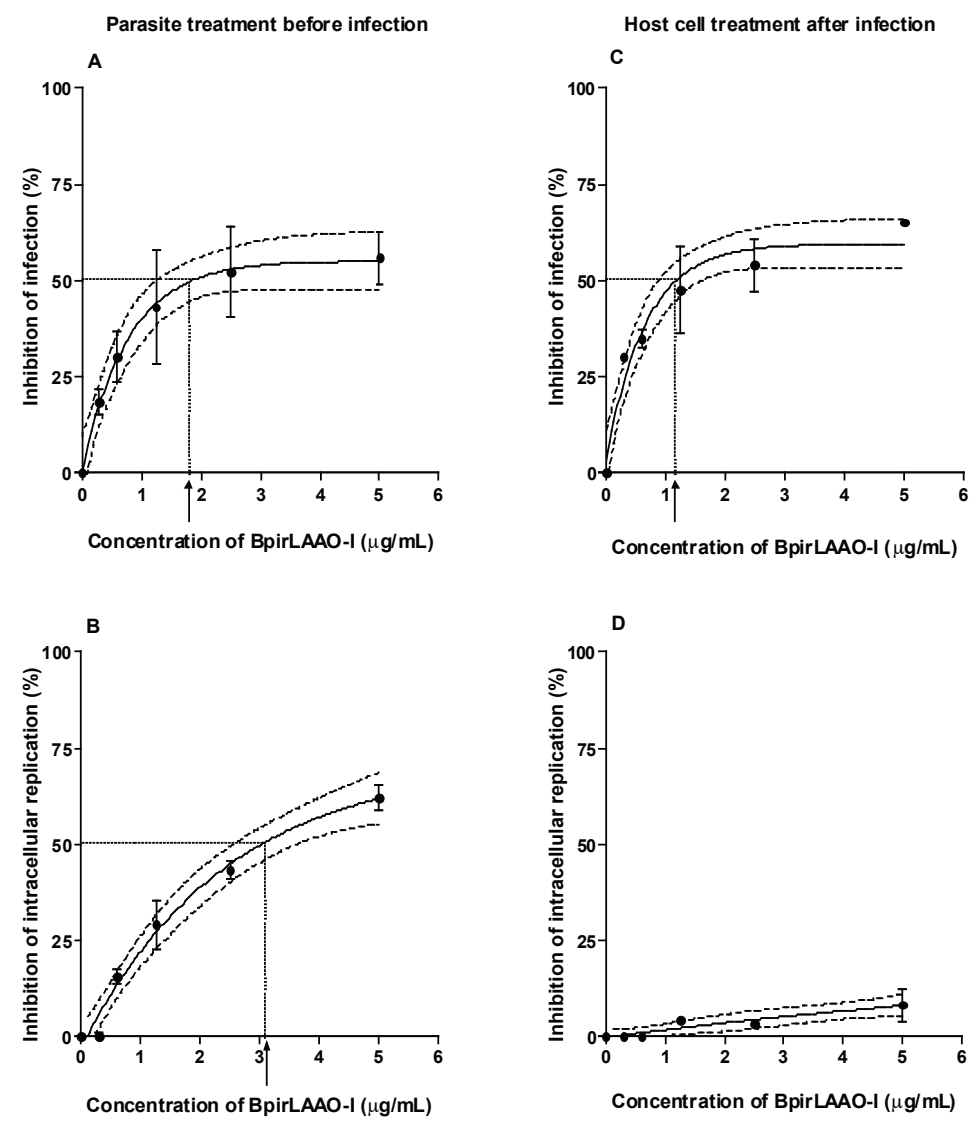

Figure 4. Effect of BpirLAAO-I treatment on inhibition of $T$. gondii infection and intracellular replication. Results of BpirLAAO-I treatment before $(\mathrm{A}, \mathrm{B})$ or after $(\mathrm{C}, \mathrm{D})$ infection are expressed as mean and standard deviations of percentages of infection inhibition in relation to the untreated controls and plotted in a nonlinear regression sigmoidal dose-response curve with $95 \%$ confidence intervals. Dotted lines show the BpirLAAO-I concentration that corresponds to $50 \%$ of infection or intracellular replication inhibition. The arrows indicate the median inhibitory doses (ID50).

during the specific catalytic activity (Ponnudurai et al., 1994). This hypothesis can be supported when catalase is added to the medium in experimental conditions, when the toxic activity is totally abolished (Toyama et al., 2006; Izidoro et al., 2006; Rodrigues et al., 2009; Ciscotto et al., 2009).

In the present study, the effects of BpirLAAO-I were also evaluated on the infection index of $T$. gondii in human fibroblasts. It was demonstrated that BpirLAAO-I induced considerable dose-dependent decrease in this infection parameter in the two experimental conditions, treatment of tachyzoites before infection and treatment of host cells after parasite infection. However, the values of ID50 and SI indicate lower inhibitory dose and higher selectivity index when LAAO was given to previously infected cell cultures, indicating that BpirLAAO-I seems to have higher efficacy in inhibiting the infection index in this experimental condition. These findings could be due to a probable effect of BpirLAAO-I on tachyzoites freshly released from cellular lysis, thus preventing the infection of new surrounding fibroblasts, rather than a direct effect or interaction with the host cell. Although all infection indexes were lower when the host cell treatment was done after infection, including the untreated controls, the dose-dependent decrease in this infection parameter was similar when the parasite treatment was done before infection. It is worthy to note that the two groups of experiments were performed independently in triplicate samples, with their respective untreated controls. Therefore, the differences observed in the infection index between both groups of experiments could be attributed to intraassay variations of each experimental condition that were minimized by using the untreated controls, as well as by analyzing the inhibition percentages in relation to controls for each experimental group.

Accordingly, T. gondii tachyzoite replication inside the host cells happens at each 6 and $8 \mathrm{~h}$, which may result in host cell lysis and infection of new 
neighboring cells (Black \& Boothroyd, 2000). It is worthy to note that in our experimental design we used a parasite:host-cell ratio relatively high $(5: 1)$ that could lead to invasion of plus than one tachyzoite to a single host cell. Consequently, multiple generations of daughter-parasites may be replicating by endodyogeny inside a single host cell, which may result in its lysis even before $24 \mathrm{~h}$ of infection. However, when the parasite intracellular replication was analyzed, the condition of treatment before infection was also successful in reducing parasitism, although with higher values of ID50 and correspondently lower values of SI. These findings suggest that this reduction in parasite numbers could also be the result of the initial infection inhibition rather than a replication specific inhibitory effect. On the other hand, the treatment after infection was not effective, since no ID50 or SI values could be determined, suggesting that the enzyme seems to cause no effect on the parasite intracellular replication for this condition. It is noteworthy that BpirLAAO-I is a glycoprotein with molecular mass of $130 \mathrm{kDa}$ and possibly does not easily enter cells and reach parasitophorous vacuoles lodging $T$. gondii tachyzoites. Therefore, these findings reinforce that the effect of BpirLAAO-I is more likely directed to tachyzoites freshly released from infected lysed cells, with consequent decrease of the infection index of new host cells.

Recently, we observed anti-parasitic activity against tachyzoites of $T$. gondii with another class of snake toxin, a metalloproteinase named neuwiedase purified from Bothrops neuwiedi (Bastos et al., 2008). This enzyme acts by degradating proteins expressed in fibroblast extracellular matrix responsible to maintain adhesion of the cellular monolayer, especially laminin, which is involved in the process of parasite invasion (Rodrigues et al., 2009; Bastos et al., 2008). In this context, BpirLAAO-I can also act in the extracellular matrix by inducing oxidative changes and preventing its use by the parasite as a mediator to access the receptors of laminin found in the membrane of the host cells, thus reducing the infection rates in fibroblasts.

When the rates of infection inhibition were compared between both studies, maximal infection inhibition rates around 71 and $61 \%$ were found for the neuwiedase treatments after and before infection, respectively, which were slightly higher as compared to the BpirLAAO- 1 treatments (65 and 56\%, respectively). However, when the selectivity indexes for infection inhibition were compared, higher SI values (6.45 and 9.83) were found for BpirLAAO-I treatments before and after infection, respectively, as compared to lower SI values (1.62 and 2.58) for the neuwiedase toxin (Bastos et al., 2008), indicating that BpirLAAO-I seems to be more effective than neuwiedase for this infection parameter.

After invasion of the host cell, T. gondii tachyzoites are located inside parasitophorous vacuoles constituted mostly by membranous material coming from the parasite (Dubey et al., 1998; Black \& Boothroyd, 2000). During the endodyogeny process, the original plasmalemma of the invading tachyzoites is used to involve the generated daughter cells. In the present study, when the tachyzoite was pretreated with BpirLAAO-I before infection, it is possible that some parasite components might have been submitted to the oxidative action of this enzyme. As a result, these components can lose the integrity of some proteins, which might harm the functional activity of the vacuole as much as the formation of the plasmalemma of the daughter cells, thus reducing parasite intracellular replication. It is also possible that the enzyme signals the parasite to induce premature egress. Further studies should be conducted to clarify the actual mechanisms of action of BpirLAAO-I on T. gondii infection and replication, by analyzing the early time points after infection. Bastos et al (2008) found similar results with dose-dependent inhibition of $T$. gondii intracellular replication after previous treatment of tachyzoites with the snake metalloproteinase neuwiedase.

The research for new active principles and the development of more effective drugs has been largely investigated in the treatment for toxoplasmosis, due to the considerable side effects of the conventional therapy (Montoya \& Liesenfeld, 2004; Carruthers, 2006; Martins-Duarte et al., 2006; Petersen, 2007). Thus, the effects of the BpirLAAO-I described herein could be taken into account for the development of new generation of synthetic or recombinant therapeutic antiparasitic agents. In addition, these findings support the importance to study ophidian enzymes not only for a better understanding of their role in the envenomation mechanism, but also because of their potential applications as biotechnological tools.

\section{Acknowledgements}

This work was supported by Brazilian Funding Agencies (Conselho Nacional de Desenvolvimento Científico e Tecnológico, Coordenação de Aperfeiçoamento de Pessoal de Nível Superior and Fundação de Amparo à Pesquisa do Estado de Minas Gerais).

\section{References}

Ande SR, Kommoju PR, Draxl S, Murkovic M, Macheroux P, Ghisla SME 2006. Mechanisms of cell death induction by L-amino acid oxidase, a major component of ophidian venom. Apoptosis 11: 1439-1451. 
Bastos LM, Oliveira Júnior RJ, Silva DAO, Mineo JR, Vieira CU, Teixeira DNS, Homsi-Brandeburgo MI, Rodrigues VM, Hamaguchi A 2008. Toxoplasma gondii: Effects of neuwiedase, a metalloproteinase from Bothrops neuwiedi snake venom, on the invasion and replication of human fibroblasts in vitro. Exp Parasitol 120: 391-396.

Black MW, Boothroyd JC 2000. Lytic cycle of Toxoplasma gondii. Microbiol Mol Biol Rev 64: 607-623.

Bradford MM 1976. A rapid and sensitive method for the quantitation of microgram quantities of protein utilizing the principle of protein dye binding. Anal Biochem 72: 248-254.

Butzke D, Hurwitz R, Thiede B, Goedert S, Rudel T 2005. Cloning and biochemical characterization of APIT, a new L-amino acid oxidase from Aplysia punctata. Toxicon 46: 479-489.

Carruthers VB 2006. Proteolysis and Toxoplasma invasion. Curr Opin Microbiol 36: 595-600.

Ciscotto P, Machado de Ávila RA, Coelho EA, Oliveira J, Diniz CG, Farias LM, Carvalho MA, Maria WS, Sanchez EF, Borges A, Chávez-Olórtegui C 2009. Antigenic, microbicidal and antiparasitic properties of a L-amino acid oxidase isolated from Bothrops jararaca snake venom. Toxicon 53: 330-341.

Costa FLS, Rodrigues RS, Izidoro LFM, Menaldo DL, Hamaguchi A, Homsi-Brandeburgo MI, Fuly AL, Soares SG, Selistre-de-Araújo HS, Barraviera B, Soares AM, Rodrigues VM 2009. Biochemical and functional properties of a thrombin-like enzyme isolated from Bothrops pauloensis snake venom. Toxicon 54: 725-735.

Denkers EY 2003. From cells to signaling cascades: manipulation of innate immunity by Toxoplasma gondii. FEMS Immunol Med Microbiol 39: 193-203

Dubey JP, Lindsay DS, Speer CA 1998. Structures of Toxoplasma gondii tachyzoites, bradyzoites, and sporozoites and biology and development of tissue cysts. Clin Microbiol Rev 11: 267-299.

França SC, Kashima S, Roberto PG, Marins M, Ticli FK, Pereira JO, Astolfi-Filho S, Stábeli RG, Magro AJ, Fontes MRM, Sampaio SV, Soares AM 2007. Molecular approaches for structural characterization of Bothrops L-amino acid oxidases with antiprotozoal activity: cDNA cloning, comparative sequence analysis, and molecular modeling. Biochem Biophys Res Commun 355: 302-306.

Iijima R, Kisugi J, Yamazaki M 2003. L-amino acid oxidase activity of an antineoplastic factor of a marine mollusk and its relantionship to cytotoxicity. Dev Comp Immunol 27: 505-512.

Izidoro LFM, Ribeiro MC, Souza GR, Sant'Ana CD, Hamaguchi A, Homsi-Brandeburgo MI, Goulart LR, Beleboni RO, Nomizo A, Sampaio SV, Soares AM, Rodrigues VM 2006. Biochemical and functional characterization of an L-amino acid oxidase isolated from Bothrops pirajai snake venom. Bioorg Med Chem 14: 7034-7043.

Jones-Brando L, D'Angelo J, Posner GH, Yolken R 2006. In vitro inhibition of Toxoplasma gondii by four new derivatives of artemisinina. Antimicrob Agents
Chemother 50: 4206-4208.

Kim YA, Sharon A, Chu CK, Rais RH, SafarjalanI ONA, Naguib FMN, Kouni MH 2007. Synthesis, biological evaluation and molecular modeling studies of $\mathrm{N}^{6}$-benzyladenosine analogues as potential antitoxoplasma agents. Biochem Pharmacol 73: 15581572.

Kitani Y, Kikuchi N, Zhang G, Ishizaki S, Shimakura K, Shiomi K, Nagashima Y 2008. Antibacterial action of L-amino acid oxidase from the skin mucus of rockfish Sebastes schlegelii. Comp Biochem Physiol Part B 149: 394-400.

Martins M, Molina FB 2008. Répteis: panorama geral dos répteis ameaçados do Brasil. In: Fonseca G, editor. Livro vermelho das espécies da fauna brasileira ameaçadas de extinção, Brasília: Ministério do Meio Ambiente e Fundação Biodiversitas, p. 326-373.

Martins-Duarte ES, Urbina JA, Souza W, Vommaro RC 2006. Antiproliferative activities of two novel quinuclidine inhibitors against Toxoplasma gondii tachyzoites in vitro. J Antimicrob Chemother 58: 59-65.

Miller CM, Boulter NR, Ikin RJ, Smith NC 2009. The immunobiology of the innate response to Toxoplasma gondii. Int J Parasitol 39: 23-39.

Mineo JR, Camargo ME, Ferreira AW 1980. Enzyme-linked immunosorbent assay for antibodies to Toxoplasma gondii polysaccharides in human toxoplasmosis. Infect Immun 27: 283-287.

Montoya JG, Liesenfeld O 2004. Toxoplasmosis. Lancet 363: 1965-1976.

Mosmann T 1983. Rapid colorimetric assay for cellular growth and survival: application to proliferation and cytotoxicity assays. J Immunol Methods 65: 55-63.

Moustafa IM, Foster S, Lyubimov AY, Vrielink A 2006. Crystal structure of LAAO from Calloselasma rhosdostoma with an L-phenylalanine substrate: insights into structure and mechanism. J Mol Biol 364: 991-1002.

Nan A, Croft SL, Yardley V, Ghandehari H 2004. Targetable water-soluble polymer-drug conjugates for the treatment of visceral leishmaniasis. J Control Release 95: 115-127.

Nuutinen JT, Timonen S 2008. Identification of nitrogen mineralization enzymes, L-amino acid oxidases, from the ectomycorrhizal fungi Hebeloma spp. and Laccaria bicolor. Micol Res 112: 1453-1464.

Oliveira CF, Lopes DS, Mendes MM, Honsi-Brandeburgo MI, Hamaguchi A, Alcântara, TM, Clissa PB, Rodrigues VM 2009. Insights of local tissue damage and regeneration induced by BnSP-7, a myotoxin isolated from Bothrops (neuwiedi) pauloensis snake venom. Toxicon 53: 560-569.

Petersen E 2007. Toxoplasmosis. Semin Fetal Neonatal Med 12: 214-223.

Ponnudurai G, Chung MC, Tan NH 1994. Purification and properties of the L-amino acid oxidase from Malayan pit viper (Calloselasma rhodostoma) venom. Arch Biochem Biophys 313: 373-378.

Rodrigues RS, da Silva JF, Boldrini-França J, Fonseca FP, Otaviano AR, Henrique-Silva F, Hamaguchi A, Magro AJ, Braz AS, dos Santos JI, Homsi-Brandeburgo MI, Fontes MR, Fuly AL, Soares AM, Rodrigues VM 2009. 
Structural and functional properties of Bp-LAAO, a new L-amino acid oxidase isolated from Bothrops pauloensis snake venom. Biochimie 91: 490-501.

Sharif M, Ziaei H, Daryani A, Ajami A 2007. Seroepidemiological study of toxoplasmosis in intellectual disability children in rehabilitation centers of Northern Iran. Res Dev Disabil 28: 219 224.

Stábeli RG, Sant'ana CD, Ribeiro PH, Costa TR, Ticli FK, Pires MG, Nomizo A, Albuquerque S, Malta-Neto NR, Marins M, Sampaio SV, Soares AM 2007. Cytotoxic L-amino acid oxidase from Bothrops moojeni: biochemical and functional characterization. Int J Biol Macromol 41: 132-140.

Tempone AG, Andrade HF, Spencer PJ, Lourenço CO, Rogero JR, Nascimento N 2001. Bothrops moojeni venom kills Leishmania spp. with hydrogen peroxide generated by its L-amino acid oxidase. Biochem Biophys Res Commun 280: 620-624.

Tempone AG, Melhem MSC, Prado FO, Motoie G, Hiramoto RM, Antoniazzi MM, Haddad CFB, Jared C 2007. Amphibian secretions for drug discovery studies: a search for new antiparasitic and antifungal compounds. Lett Drug Des Discov 4: 67-73.
Tenter AM, Heckeroth AR, Weiss LM 2000. Toxoplasma gondii: from animals to humans. Int J Parasitol 30: 1217-1258.

Toyama MH, Toyama DO, Passero LFD, Laurenti MD, Corbett CE, Tomokane TY, Fonseca FV, Antunes E, Joazeiro PP, Beriam LOS, Martins MAC, Monteiro HSA, Fonteles MC 2006. Isolation of a new L-amino acid oxidase from Crotalus durissus cascavella venom. Toxicon 47: 47-57.

Zieler H, Keister DB, Dvorak JA, Ribeiro JM 2001. A snake venom phospholipase $A(2)$ blocks malaria parasite development in the mosquito midgut by inhibiting ookinete association with the midgut surface. $J$ Exp Biol 204: 4157-4167.

\section{*Correspondence}

José R. Mineo

Laboratório de Imunoparasitologia, Instituto de Ciências Biomédicas, Universidade Federal de Uberlândia Av. Pará, 1720, 38400-902 Uberlândia-MG, Brazil jrmineo@ufu.br

Tel. +553432182058

Fax +553432182333 